\title{
'Aimless and Absurd Wanderings'? Children at the Museum of Old and New Art (Mona)
}

\author{
Adrian Franklin*, Michelle Sansom**
}

\begin{abstract}
This article reports on the experience of children at the Museum of New and Old Art (Mona) in Hobart, Tasmania. Referred to by its innovative owner as a 'subversive adult Disneyland', Mona went further than most new contemporary art galleries in designing a radically new experience of art. It captured the imagination of people new to art in its own locality as well as a global art public. Favoured by leading international contemporary artists for the freedom it gave art unmediated by art history, Mona also seemingly captured the imagination of children. Through an ethnographic approach in which five young children's visits were documented in great detail, the article considers these in the light of children's experiences of previous exhibitionary platforms and the relevance of Mona's museological interventions for building their dispositions to art and broadening art publics.
\end{abstract}

Key words: Children, art museums, art publics, ethnography, museology.

\section{Introduction}

This paper considers whether, among the many transformations of art museum experience claimed for Mona (Timms 2011a, 2011b; O'Connor 2013; Capon 2013; Franklin 2014) there is also evidence that it has significantly transformed children's experience of art in museum settings. First, the literature on children in art museums is considered critically in the light of their historical development and repeated recent calls to better integrate children into art publics (Roberts 2006: 155). Second, we outline Mona's radical aims and impacts, including its overarching aim to subvert the conventional art museum and realize a very thoroughgoing embodiment of the 'anti-museum' (Lorenz 2011; Smith 2012). The paper then reports on an in-depth empirical study of children at Mona during which the visits of five eight-year olds were tracked and documented in great detail. It clearly shows how the radical freedom of movement at Mona, its strong elements of induced wonderment and its theatricalized architecture and exhibition design induced very intense and personalized forms of engagement as well as longer and aesthetically immersive museum tours. Freed from demands to negotiate specific elements of art history as a 'takeaway', the children developed their own subjective understanding of the artworks, understood how they relate to their lives, and glimpsed its meaningfulness. It provides a provisional sense of how children's engagement with Mona is also mediated by the habitus of their family and new sources of variation in parental engagements with the contemporary art world and culture industries.

\section{Children and the Modern Art Museum}

During the eighteenth century private art collections opened to a broad public. Then, the ideal of the 'public' was synonymous with adult 'polite' society, those who were 'literate and could be trusted to behave themselves'(Hudson 1975: 27). The Society of Art regretted their free exhibition of contemporary art in 1760, which became: 'crowded and incommoded by the intrusion of great numbers whose station and education made them no proper judges of statuary or painting and who were made idle and tumultuous by the opportunity of a show' (Hudson 1975: 15). Similarly,the British Museum had required visitors to make a written application for 
a three-hour viewing and specifically excluded children under ten years (Hudson 1975: 10).

A turning point came in the early nineteenth century when culture became a tool of governance and was embraced as a mechanism of power (Foucault 1980). Museums, libraries and parks were used as cultural discipline, contributing to the politically quietened moral and behavioural ideals of industrial capitalism, and children came into such a frame to be socialized early (Bennett 1995: 21). During the 1850s, museums experimented with 'public days' that provided unrestricted public access, including to children. By 1855, The South Kensington Museum invoked a policy change to service an undifferentiated public with great success: fifteen million visitors attended between 1857 and 1883 (Bennett 1995: 70). The museum transformed into a space where civilized behavior could be emulated, with collections arranged to educate the public through simple classificatory devices: chronology, taxonomy, 'progress'.

Children were a conundrum for early art museums because they were often too young or 'untutored' to engage effectively with their pedagogical aims and technologies (of labels and guides) (Bennett 1995). A number of studies have since discovered that children respond most positively to unmediated art (Weiner 2004; Jeffers 1999). Children under ten years of age experience art in a physical way; they are loud, run in the open spaces, and are curious and interactive (Weiner 2004: 107). Art inspires embodied reactions and responses. Their reaction is also emotional, intuitive and subjective; an embodied reaction that conforms neither to the reverence nor the quiet contemplation required by most exhibitionary platforms. Yet, the history of art museums shows them to have become increasingly hived off from the main museum and given age-specific experiences of art.

From the turn of the twentieth century, children were widely separated into their own museum spaces. In some, their exuberant behavior was curbed/confined and their education predetermined. In 1921 the Tasmanian Examiner reported a funding request to establish a children's room with age appropriate displays that would: ' . . attract their attention and educate their mind... (halt) their aimless and absurd wanderings....among specimens that can have no possible meaning... (and not) distract the attention of would-be students and introduce an atmosphere of unrest' (Examiner 1921: 7).

Other children's museum rooms and wings of museums in this period were influenced by the ideas of John Dewey and Maria Montessori who encouraged learning through manipulating and exploring materials - where handling and discovery, if not play, was encouraged (Mayfield 2005: 180). With art objects this was always problematic. In the 1960 s the influence of Piaget and Spock saw a proliferation of museum spaces, so that by 1990 in the USA alone there were 280 children's museums. According to Mayfield's (2005) study of 25 children's museums, learning and instruction were the key values picked up via content analysis: learning and instruction was expressed in three out of five categories of stated goals, creativity was stressed in one, and 'learning through play' in another.

Similarly, the new museology in art museums aimed to provide experiences to more diversified, niche audiences that supported their pedagogical aim in art history (Griffin 2011: 1-2). In 1998, The Children's Art Centre at Queensland Art Gallery established a children's exhibitions space that 'empowered' them through self-directed learning (Piscitelli 2011: 2). Art museums also pursued the family as a key audience, providing 'family based' museum experience rather than experiences directed to individuals of specific ages (McManus 1994: 82-83; Hicks 2005; Piscitelli 2011: 2; Griffin 2011).

Because of this dominant focus on didacticism and learning, Weiner (2004) argues that children still tend to see most art museums as large and imposing places. Their architectures, uniformed (security) attendants, hushed reverence and art hung at adult height do not provide children with the comfort to explore in a manner best suited to their needs. The museum sends an unconscious message to the child that they are not welcome (Weiner 2004: 106). Yet Jeffers (1999: 50) argues that when a child does connect with an art museum they have the capacity to express unique perspectives and insights. Unlike adult visitors they do not feel compelled to be, or to emulate experts and are open-minded and spontaneous in their response to the art. Typically their response is embodied and intuitive, expressed through role-playing, singing, dancing, facial gestures and noise (Weiner 2004: 106-107). By and large this is still neither encouraged nor allowed. None of these are prohibited at Mona. Even the art works are noisy and unruly at Mona. 
Mona's intervention was diametrically opposed to the goals of children's museum spaces. It removed all directions and didactic cues (or expectations) and inserted a radical informality instead (Franklin 2014). Visitors were to be properly free floating, spontaneous and unstructured, forcing visitors of all ages to encounter the environment of a gallery and its art on their own terms. It would seem to chime well with children's natural predisposition towards art. But how did they respond to such an unconventional art museum, and such a seemingly 'adult' collection?

\section{Mona's arrival and impact}

Soon after Mona opened in 2011 Lonely Planet referred to Hobart's transformation as 'Harbour town becomes hip' and a former Director of the Art Gallery of New South Wales said that 'In Australia, maybe the future has already arrived - at a place that redefines the term 'art gallery' (Capon 2013). Mona's redefinition and redesign was deliberate and exhaustive, as much aimed at the geometries and symbolisms of museum architectures and ordering as it was to designing a transformative experience of art and changing art museums as social, cultural and political projects. Seemingly with very serious aesthetic aspirations, the museum dubbed by its owner as a 'subversive adult Disneyland' was immediately very popular - with children (Franklin 2014). According to entry data obtained from Mona, children (persons under 18) account for 9 per cent or 31,500 of their visitors (data supplied by Mona to authors on July 26 2016). It became an essential component of a Tasmanian childhood.

At the June 18 opening of Red Queen, Mona's main exhibition for 2013, the children of the 3,500 guests formed a number of pack-like groups, occupying separate and distant areas of the exhibition, well away from their parents. They ranged widely in the theatrical darkness, the entire length and breadth of a major exhibition, often running or skipping between art works or gallery areas, but also often congregated around, in or even on particular works. Their engaged manner was striking: in so many ways they were as interested in the art as the adults.

A successful professional gambler, David Walsh had always loved museums as a child but he became their biggest fan and critic. When significant wealth came his way, his collecting and museum-building aspirations resulted in the recruitment of a team that would take some three years to rethink the art museum and its most serious shortfalls: elitism; didacticism; its disproportionate interest in art history; its stale and repetitive exhibition formating. From 2005 to 2007 they created an entirely new set of museum aims (for details see Franklin 2014) which can be reduced to four core interventions:

- Change the nature of engagement with the museum: To encourage an actively self-engaged encounter with the museum and its art by arousing/provoking states of wonderment and thought and by theatricalizing and rendering encounters with art as exciting and provocative;

- Provide new ways of accessing art: To invite visitors to determine their pathways into art experiences - to determine their own response and to discover their own voice;

- Transform visitors lives and consciousness: To provide a transformative experience - to change visitors' lives, in some way.

- Oppose art history/theory as a singular voice of authority: To populate the art gallery with the multiple subjectivities that art works generate and to encourage subjective responses from visitors and not merely 'didactic improvement'.

The 6000 square metre museum was built deep underground; it was a deliberately confusing, liminal space of darkness and shadows, with art encountered after the picturesque style, in pools of light across multiple, conjoined levels. Within the grounds, the entrance, transit spaces and galleries there are no directions, no signs, no labels, no guidance no instruction - absolutely no cues to learn. Mona's mantra is: we show, we do not tell.

They invented a smart-tech audio-visual aid (The O) on which there are multiple narratives about the artworks, a mix of art history and honest expression about the art by the collector, the artists and Mona's writer Elizabeth Pearce. In catalogues and on internet sites these narratives 
often delivered carnivalesque mocking of their art as well as their artists. Visitors were left on their own, forced to make their own decisions and think for themselves. And they rose to the challenge: they became very absorbed, lost in the times and spaces of its immersive settings. Average museum tours at Mona were up to six times longer than those recorded elsewhere (Franklin 2014; Franklin and Papastergiadis 2016). In these ways, Mona went considerably beyond the range of innovations associated with new museology (Wright 1989).

The seriousness of conventional museums was dropped in favour of wonderment, openness and humour. Mona did not aspire to the norms, standards and values of conventional museums, but opposed them, framing its museum aims around those of the anti-museum (Franklin 2018 forthcoming).

Wonderment was possibly the most important device that Mona deployed in order to arouse a new, more engaged relationship between visitors, the gallery and their art. In their view, wonderment was a deeply positive emotional-intellectual state that activated visitor engagement, aroused curiosity, doubt, excitement or humour. It was felt that much contemporary art could speak directly to the public if only it was presented in a more accessible and appealing way. It was also felt that their visitors should be treated as intelligent enough and capable enough to respond to art if the cues were not restricted to those with particular (social, culturally dispositional) advantages (and clearly this applied to many children). Rather than use an instructional pathway Mona used a wonderment pathway, which as Mona's first Museum Director Mark Fraser noted, could also lay some claim to pedagogical value. But did it work?

For the Oxford Concise English Dictionary the word 'amaze' means 'to fill with wonder' and was therefore a good common parlance term with which to probe wonderment among all of our Mona visitors. In our Visitor Survey of $2013(n=5,600)$ we asked respondents whether their time at Mona was amazing, compared to time spent at other museums. Eighty per cent of the sample stated that it was, and there was no significant variation across the cohort (see Franklin and Papastergiadis 2016).

We also wanted to know how visitors would respond to the statement: 'Compared with other galleries Mona made me think about a lot of things', since this connotes the arousal of interest and curiosity and may be interpreted as a spark that ignites the self-directed engagement that Mona was keen to encourage. Eighty per cent of respondents agreed with this statement with no significant variation by education, income or occupation. In sum, it seems that the aim to use wonderment to arouse curiosity, excitement, doubt, enchantment, interest and thought was largely effective in obtaining a positive response among our respondents, though the survey was only administered to those aged 18 and over.

Mona therefore provides an opportunity to investigate the potential for new relationships between children and art museums and to situate children within contemporary debates on expanding art publics and new museological initiatives. Most studies/surveys of art museums (including Bourdieu's) exclude children, and yet it was central to Bourdieu's analysis of distinction that adult taste and cultural capital are deeply affected by dispositions instilled within the habitus of the developing child (Bourdieu 1984). Contemporary experts using Bourdieuvian frames of analysis still link low rates of adult art museum attendance to the absence of dispositions born from effective formative influences and contact with art during childhood (Bennett 1995). Despite its clear relevance, the exclusion of children in Bourdieu's (and others) empirical work on art and distinction might be considered a serious omission.

\section{Children at Mona - an empirical study}

Historically, children were a 'muted community' (Hardman 2001) in museum studies and sociology generally. In recent years however, researchers have begun to give children a voice and presence in museological investigations (Hackett 2014; Dockett Main, \& Kelly 2011; Anderson, Piscitelli, \& Everett 2008; Larsen \& Svabo 2014). These studies employed a number of qualitative methods, including ethnographically based observations of pre-determined activities or tours, interviews with children and parents, and journals written post-visit to recall key aspects of the museum.

A number of possible methods were considered for this project. The use of a visitor exit survey designed to understand adult engagement at Mona (used by the main Mona Effect 
Study) was considered, but its language was too difficult to administer or modify for young children. Nor was it deemed necessary to obtain statistically representative data since our interest was in generating detailed accounts of how children engaged with Mona and its art, across the space and time of their tour. Other qualitative methods such as semi-structured interviews were also considered, but deemed inappropriate and difficult to undertake with young children. Interviews generally are subject to power imbalance between interviewer and interviewee and this is exacerbated when a child is interviewed (Scott 2000: 100). Further, establishing rapport with children requires trust, and to obtain that and detailed data from interviews required considerably more time than children or their families could make available. Finally, children's literacy and language skills are still developing, therefore interviewing can result in limited data (Scott 2000: 100). A small sample of Mona tours studied in great detail would generate the kind of data required to show how children comported themselves in Mona; how they interacted and engaged in a physical and embodied way with the art, its ambience and environment. Hence it was decided that a qualitative methodology that was built around participant observation was the most appropriate and unobtrusive way of understanding how children engaged with Mona.

To understand the issues associated with undertaking participant observation of children in Mona, we conducted a pilot study to establish a method of observing the engagement and behavior of children in its darkened, labyrinthine environment. These observations were made of experiences within the museum as the researcher assumed the role of fellow visitor. The timing of these observations provided an insight into children attending Mona who were not local residents since they took place on weekdays during the school holidays of mainland Australia, when Tasmanian children were still in school. It was therefore reasonable to assume that the children who attended Mona during this time with their families were visitors to Hobart. We were thus able to study and compare a Tasmanian school holiday cohort when mainland school holidays were over. From our main survey we knew that most local residents had undertaken repeat visits to Mona and we wondered whether greater familiarity produced different forms of engagement.

The pilot study provided rich observational data into a child's relationship with Mona, including their appreciation of the art, their physical and emotional reaction to the environment and key locations, and children's social interactions with parents, siblings and invigilators. Pilot observations worked best from certain vantage points close to a representative mix of art works, but this meant we could not obtain data on entire tours. We therefore decided to study a very small sample in greater depth. Five parent-child pairs were recruited as respondents, each for a single tour of Mona, in the knowledge they were being observed and overheard. In order to gain intimate knowledge of their Mona experience an audio recording of their tour was made and the $\mathrm{O}$ was used to track their passage through Mona. Field notes and end-ofday observational notes were recorded. The observations focused on the interaction of the child with Mona; their reaction to the art, architecture, technology and general atmosphere through their emotions, body language, interactions with people and points of curiosity. At the end of their tour each group was interviewed to gain an insight into the child's experience as expressed in their own words.

The parent-child dyads were recruited from one of the researchers' network of associates developed through her child's school (The Friends School, Hobart). The son of one of the researchers was also a participant. In this way it was possible to obtain very easily the general demographics of the sample group as well as background knowledge such as children's familiarity with Mona. This mitigated ethical considerations as the content and environment of Mona was known to the parents and children in the dyad groups thus allowing them to give informed consent.

The children studied consisted of three girls and two boys aged approximately eight years old, with the child's mother or father joining the observation. The inclusion of a parent in the research was an important element as the parent/child relationship is a vital component and constant in the social world of an eight-year old child, as we learned from the pilot study. The role of the parent is to regulate the child's behavior and determine acceptable exposure to concepts contained within public institutions such as museums (Prout \& James 1997: 15). Eight year olds are defined by The Australian Institute of Family Studies year olds as 'children' 
since they have not yet commenced puberty and therefore still retain the quality of 'innocence' regarding their physical development and sexual maturity that is generally associated with childhood (Edward 2014). This age group does however, hold a level of maturity to articulate and explain their opinion.

\section{Pilot observations}

The pilot observations in Mona occurred during the June/July school holiday period in 2015 when only NSW, Victoria and Queensland had commenced their holidays, for blocks of two to three hours. After the fourth day of pilot observations it was felt that no new forms of engagement were forthcoming and we terminated the pilot. However, it turned out that these observations offered a counterpoint with Tasmanian children who comprised the main in-depth study. While both groups responded to the museum in similar ways it became evident that greater access and hence familiarity with Mona had a cumulative impact, and the nature of their engagement appeared to deepen and change.

Mona is intended to be a liminal environment where the order and structure of conventional museums is rendered into a strange, topsy turvy 'antistructure' (Franklin 2014: 276-278). During the pilot study family groups appeared unsure of themselves in such a context and as they entered the museum their heads turned in wide arcs. They tended to huddle together as they contemplated a palpable atmosphere of excitement and anticipation; later they formed huddles with others around theatrically lit art objects. Families seemed to work together to experience this unknown and sometimes disorientating/disturbing sequence of experiences. That said, the majority were highly engaged with the museum.

At bit.fall (Julius Popp 2006-7), the first major art work encountered, parents and children formed tight family groups watching the art, reading the words together, questioning their meaning and sharing the information from the $\mathrm{O}$ device. The art at Mona is not exhibited in order to show chronology, taxonomy or art history, but, in the spirit of most contemporary art, to provoke a reaction from an audience who, it is believed (by Mona artists and Mona), are knowledgeable enough to engage with it. Jan Fabre speaks for many Mona artists when he told Mona Writer Elizabeth Pearce that he believes in the 'sacred bond between artists and viewer'. He trusts the public to interpret his message and appreciate his creation. He said that 'we should not dirty too much with our comments and inyerpretation' (Franklin 2014: 218). For art (and museum) critic Matthew Collings, contemporary artists now deals in subject matter such as the abject 'as if it is part of the art audience's natural cultural horizons, as something familiar.... There's no point in believing something that will only be incoherent to an audience' (Collings 2001: 134). Hal Foster has recently identified the abject, the precarious, the traumatic and the lost as symptomatic objects of what he calls (after Brecht) the 'bad new days' of neoliberal ascendency that artists now address - often through carnivalesque techniques of 'mimetic exacerbation' and 'mockery' that reach directly to knowing audiences (Foster 2015: 78-96).

bit.fall is a spectacular work that forms the currently most-used words on Google from millions of droplets of water dropping from a great height with an enlivened, rhythmic pulsing. It is like a mesmerising showground attraction and draws a big crowd who linger there for up to 10 minutes.

As the children explored Mona their confidence and comfort levels appeared to grow. For example, they began to take decisions independently of their parents, to move away from parents, to move over exhibit boundary lines and to shift into spontaneously expressive behaviour. In so doing, they claimed the gallery for themselves - in several instances suddenly leaving their parents to form children-only groups. At many points in the observations they were emotionally and physically engaged: entranced with artworks, providing loud commentaries, laughing, loosened up - often dancing or otherwise engaged in exuberant, physical movements. The freedom with which children engaged with art at Mona was notable and can be illustrated by observations made at Wim Delvoye's Cloaca (2010) and Barsamian's Artifact (2010). 


\section{Cloaca}

$1.50 \mathrm{pm}$ : a large group gathered in the Cloaca gallery with approximately twelve children (aged from 4 years to teenagers) from five family groups. The children sat on the floor in front of Cloaca. They sat silently, waiting for Cloaca to defecate and when it finally did, a series of 'oooohs' and 'look' resonated throughout the gallery. Once finished, those without children left quickly as the smell in the room intensified. It was, after all, a near perfect simulation of the human digestive system. The families remained, watching and waiting. One boy, (approximately five years old), moved from a sitting position to have a closer look. He remained behind the boundary line between the audience and artwork and inspected the new 'specimen'. His father and sibling joined him and they engaged in a conversation. The movement and exploration of this child appeared to give permission for the other children to take a closer look. They collectively moved towards Cloaca's 'anus' with the noise in the room intensifying, laughter interspersed with 'oohs', 'ahhs' and 'urghs'. One boy, who was part of the group sitting on the floor, moved up to inspect Cloaca. He became frustrated with the crowds and the line that defined the boundary of the art so he moved around to the side and stepped over the line for a closer inspection. He was the only child to move over the line and he spent the longest time looking at what Cloaca produced. After a few moments he looked to his parents to leave. Satisfaction with this close inspection was demonstrated by a broad grin and a triumphant series of pretend 'drop punts' (a form of AFL kicking) as he left the gallery.

The experience with Cloaca raised the collective energy levels of the children considerably. After leaving Cloaca most of the children and families moved up to cartoonesque figure of Edwin Wurm's Fat Car. The noise levels increased significantly with an atmosphere of fun and silliness. The children were highly animated in their demeanour, dancing and laughing as they moved towards the red Porsche rendered obese by the artist. They seemed to get the joke about excess.

At other art works the children were not only immersed in the spectacle and entertained, they were clearly engaged with the particularity and detail of the art. Here is an exerpt from notes made during an observation at Artifact:

They were drawn to this head lying sideways on the ground and its various peepholes; they pressed their faces closely to the art to view the representation of a brain. One 'peephole' viewers to kneel was much favoured by children. One child (aged c.5) stood at the exhibit with his face pressed into a peephole calling out the things he could see 'bird, black slug, apple, black slug being eaten, maybe it is not a black slug'. The volume of his voice and the smile on his face betrayed total absorption. Another girl, approximately 8 years of age, knelt at the preferred peephole to watch inside Artifact. She sat with her face pressed up to the art for approximately 5 minutes. When she pulled away she had been so entranced that she lost her mother and sister and had to ask the invigilator to help find them. Again, their engagement with the art detached them temporarily from their dialogue with, and oversight of their parents.

While displaying a relatively high degree of spontaneous and engaged behaviour, it was also noticeable, from these vignettes, that their confidence grew the more they were in the museum.

We were interested in how this might progress with subsequent visits and so looked forward to the more intensive observations of the main Tasmanian study group who had far more opportunities to attend Mona. The following section reports on the five in-depth parent childtours of Mona, first by detailing one tour in some depth and then showing how the others approximated to, or diverged from it.

\section{Five Children Tour Mona}

Our sample of five Tasmanian eight year olds had all been to Mona many times before, with 
their families and with their school. ${ }^{1}$ We observed one complete tour with each of them during August 2015.

First we provide, in some detail, how one of the children, Margaret and her mother Kate, toured Mona. Then, on the basis of this, we will show the extent to which the others varied from it.

\section{Margaret}

Margaret comes from a middle class family, the younger of two girls. Her parents are both professionals (her mother a school teacher and her father a senior information technology manager). In Kate's words 'art is an important part of their family': Margaret's father is an amateur creative photographer and her maternal grandfather was an acknowledged amateur artist. Margaret is a quietly confident girl. She is accomplished in sport, intelligent, and popular amongst her peers.

When Margaret arrived she was clearly buoyant, alert and engaged. She seemed very happy to be at Mona again and clearly knew her way around the main precinct.

As they moved to Mona's entrance Margaret became more pensive and held her mother's hand. This continued as they received their tickets and were given instructions by the front-of-house staff about Marina Abramovic's Scream Room and a potentially inappropriate film installation. The invigilator offered a map and although Margaret initially took one she quickly put it back, saying to Kate she did not want it. It became quickly obvious that she did not need it. Moreover, from that moment on Margaret, rather than her mother, determined both the direction and the content of their tour together. Indeed, what is so interesting about Margaret's visit is the extent to which Mona appeals to her, and the extent to which she is drawn into it as a place of imagination, play and exploration. Her museum visit documented below demonstrates that to a significant extent she abandoned the adult-directed world of her mother and museum staff, to be alone with Mona.

Eschewing the downward spiralling stairs, Margaret determined that they should catch the theatrical, Archigram-styled lift to the lower galleries. She knew how to operate it.

At the bottom, Margaret and Kate entered The Void bar area, received their $\mathrm{O}$ devices and were told by the invigilator that they were easy to use. Margaret recognized her environment, she physically relaxed and wandered five paces ahead of her mother towards bit.fall. Kate pointed out the walls and the furniture, but Margaret only gave them a cursory look: she was preoccupied with her $\mathrm{O}$. She quickly reacquainted herself with the device, placed the headphones on her ears and the strap around her neck and began listening to the audio track for bit.fall. This was music, and Margaret encouraged Kate to listen, giving her instructions on how to achieve this task on the O. Margaret and Kate discussed the machinations of bit.fall, considered what the words represented and how they were formed. Margaret was curious about its mechanical and technical aspects. Once she received confirmation that the museum really got wet as a result of the art she was ready to move on.

Margaret moved towards the Abramovic exhibition. She stopped at the entrance noticing Artist Portrait With A Candle, From The Series "Places Of Power". It shows Abramovic holding a candle with her finger over a naked flame. With a concerned look she checked with Kate who confirmed that it would hurt and that the artist was indeed inflicting pain on herself. She then searched the $\mathrm{O}$ for the artwork.

Margaret was now less confident as she entered the first gallery. It was dark and screams could be heard as background noise. She made sure Kate was with her by holding her hand and standing close. She was relieved to see Rest Energy and discussed with Kate how the projector worked. She physically mimed the performance by standing and holding a pretend bow in her hands. They were the only group in the gallery. She turned to move away from the exhibit but noticed Point of Contact that involved fingers touching, which she discussed with Kate. Margaret was anxious about the screams coming from the next gallery and hesitant to move on. Kate took her hand and they walked slowly into the next gallery. Kate lowered her body so they were the same height and they put their arms around each other. Feeling more comfortable, Margaret began to explore the art with her mother, they discussed it in some depth and worked through what it represented. They both periodically searched their $O$ to increase 
their understanding. Margaret then left Kate and looked at the art alone. She politely moved around the other guests in the room to look at $A A A-A A A$ and Freeing the Voice.

Margaret was immediately drawn to Cleaning the Mirror I. A smiling and animated Margaret identified the body parts that were being cleaned. She appeared very satisfied with her anatomical knowledge. Now very self-assured, she spontaneously announced that she wanted to see Fat Car and looked to move into The Chamber of Silence to progress through to the upper galleries. The invigilator stopped their progress and re-directed them back through the Video Screen Gallery and through the tunnel. Kate checked to see if Margaret was okay with these instructions, she nodded her assent but had lost her smile, her head dropping slightly. Margaret moved quickly through the Video Screen Gallery without reference to the art and up the tunnel. Kate started to discuss the tunnel but Margaret ignored her, gave a cursory viewing to Golden Mask by referencing the $O$ then stated she wanted to see Fat Car. Ignoring the invigilator's directions, Margaret moved ahead of her mother back down the tunnel straight through the Video Screen Gallery and Confession Gallery, past the invigilator and through The Chamber of Silence. She was determined, moved quickly and did not defer to anyone. We can note here the development of what might be called 'personal routemaking' between new and favourite works among repeat child visitors and the collapse of the museum as an adult-directed experience.

Ignoring the Egyptian exhibit and an invigilator who pointed out a potentially inappropriate video installation to Kate, Margaret arrived at Fat Car. She circled the art, inspected the number plate and completed a stocktake that the car was as she remembered it. Due to the warning by the invigilator Kate was on high alert looking for the inappropriate video and was relieved that Margaret chose to enter Queen. The Portrait of Madonna. Margaret sat and watched the screens and smiled enjoying the artwork. She looked to leave and walked back past Fat Car to make her way down to Cloaca. She held her nose as she entered the exhibit and moved straight to its 'anus' where a relatively new specimen was available to inspect. She spent time with Kate discussing the biological elements of the art, acknowledged Cloaca as one of her favourite artworks due to its representation of the human body and moved out of the gallery.

Margaret moved around the circular maze of Kryptos, touching the walls and pressing her hands against the glass displays. When she reached the end she moved quickly into the square space, stroking the walls as she looks up at herself in the mirror. She touched the letters/numbers and discussed the concept of binary with Kate. She moved onto her knees and explored under the floor pulling out a wire that Kate told her to put back. This signalled time to leave and Margaret walked out of the exhibit touching the walls, stating the room felt like a grave.

Upon re-entering the Nolan Gallery Margaret declared that she had seen everything she wanted to. She had spent an hour and fifteen minutes in the galleries.

Margaret's intense museum tour was a mixture of repeat visits to well-known works that she loved, and enjoyed seeing again, as well as visiting a new exhibition (by a famous living artist) and encountering other works that were fresh and suprising to her - the result of Mona's daily and seasonal changes of its hang. It seemed that her familiarity with the museum and the main collection gave her confidence to launch into new encounters as much as renew the pleasure to be gained from memorable favourites. Her tour was intriguingly energetic, very far from the sauntering pace of most museum-going. She positively rushed with great gusto between areas and works, but then she gave certain works intense attention. She was mostly a law unto herself, though this was interspersed with periods where she conferred closely with her mother. It was as if she divided her time quite consciously between time alone with art and time enjoying it or interrogating it with another - oscilating between a child's subjective viewpoint and a wider adult worldview.

\section{Chris, Olivia, Anne and Lucas}

The four other children also attended The Friends School, Hobart, where they had been exposed to art from prep through a dedicated art program and school excursions to Mona and the Tasmanian Museum and Art Gallery. Like Margaret they each come from families with two parents and siblings and their parents came from working class or lower middle class 
backgrounds, were tertiary educated and employed in professional/managerial or specialist roles in the medical, education, financial, cultural and public service fields. They enjoy relatively high disposable incomes that enable a level of privilege in terms of education and leisure. With one exception, all families acknowledged the benefit of art. Many of the observations of the other children were similar to Margaret, so the following section will illustrate where they diverged and discuss possible sources of variation.

The girls were very similar in their reaction to, and experience of Mona. At times they were pensive, particularly at the beginning and near the Scream Room. However broadly speaking their tours reflected their confidence and familiarity with the museum as they freely expressed their emotions and only required parental guidance when unsure of a social convention. Each of the girls found art that they intuitively and emotionally responded to. Olivia had a personal reaction to the Transitory Object Gallery whilst Anne was moved by and explored Waterfall. The girls expressed enthusiasm through words, recalling personal experiences but also as an embodied reaction: there was much noting of smells and noises, skipping and touching (many artworks were felt as much as seen).

The boys' tours in this study differed markedly from the girls'. The girls openly enjoyed and engaged with the experience whereas the boys were less enthusiastic or engaged in a diffferent way. It is notable, perhaps, that two thirds of the adult visitor population at Mona are women (Franklin and Papastergiadis 2017) and men often appear less enthusiastic.

\section{Lucas}

At the Abromovic exhibition that had so aroused Margaret's curiosity, Lucas was ambivalent and uncommitted. In the first gallery of three works that included 'Rest Energy', (a bow and arrow being held between two people) Lucas looked at the art with a neutral expression. $\mathrm{He}$ was less focussed on the art and continued to look and fiddle with the $\mathrm{O}$, stopping to read the initial explanation when it registered the art in front of him. They then moved into the Scream Room. The noise of screaming people confronted Lucas as he was physically taken aback by the noise. When asked by his father if he wanted to scream the answer was firmly 'no', and he looked to move on.

They sat in Queen. A Portrait of Madonna for an extended period of time. This was a place that his father and sister really enjoyed. Lucas seemed ambivalent to the art and music. He used the time to rest rather than be absorbed by the art on display. He was starting to get restless and a little bored and he needed something to excite him and this display held little interest. The two vignettes capture his general demeanour throughout.

\section{Chris}

Chris moved confidently down the stairs to the museum on level B3. He occasionally looked behind him to ensure Andrea was with him but moved along quickly and alone. He knew Mona backwards and was looking for new elements which had arrived since his last visit.

He proceeded to review what was on offer. He commented that Nolan's Snake was different, he moved to the fish bowl which was new to him and said that the bowl made the fish look as though they were swimming without water.

In the first Abramovic gallery he studied the three pieces of art. His arms were crossed and he had a pensive, contemplative expression on his face as he deliberately studied each piece. The expression on his face showed little emotion as he studied the works. Adult-like.

In the next room Chris and his mother spent time discussing art objects in a chest of drawers. They opened each one and studied the content. Andrea did not need to encourage his attention; it seemed natural for them to look at this together, to discuss it and what the artist was trying to achieve with their work. Andrea mentions high-level concepts such as power, Chris thinks and considers the answers he provides.

Chris's family considers art to be of primary importance. He has been to Mona in excess of twenty times since it opened. His mother is employed in the culture industries and considers art to be part of 'her essence' with a substantial amount of their leisure time consumed by visiting museums. Chris's habitus exposes him to high levels of culture and this is reflected in 
his cultural capital and experience in Mona. Chris's behaviour in Mona was less about individual exploration and was more organized, intellectualized and sophisticated. Chris was discerning and highly informed by art history and knowledge of art forms and sub-fields. He considered the artists' intention and referenced changes to art and its exhibition.

By comparison Lucas had less exposure to cultural activities involving art. His father and mother's careers are based in financial services. The family are more orientated to popular theatre in its various forms and prefer sporting events to art museums. When visiting Mona Lucas' demeanour was less animated; at times he appeared bored and his commentary about the art was limited. When asked what aspect of Mona he enjoyed he acknowledged Cloaca but only really became enthusiastic when discussing the technical aspects of the $O$.

\section{Conclusions}

This research suggests that museum experiences for children at Mona are especially engaged, embodied, playful and personalized. Regular Mona-going adds significant degrees of familiarity, ownership and knowledgeability to the spontaneous responses observed among first-time goers from interstate homes. However we can also conclude that gender, class, occupation and cultural capital do mediate their experience of art in Mona. Given its popularity Mona is likely to change the pattern of dispositions to art among children, though the extent to which it changes those generated through gender, class and occupation will require more extensive testing. It is interesting to note, however, that from a Bourdieuvian perspective, significant levels of cultural capital and dispositions do emerge in children who are regularly exposed to art while those who are not find it more difficult to access its value. This, however, did not depend on the habitus typical of traditional nineteenth-century elite families, whose homes were full of acquired art collections, but exposure to art in the much expanded cultural milieu of the twenty first century, among middle class families who pursue art as a lifestyle, through their employment in cultural industries and leisure. There are seemingly multiple pathways to the acquisition of dispositions and this too needs to be factored into larger scale survey approaches. This research offers a way of interpreting and understanding the dispositional impact of different intellectual disciplines and career paths rather than tertiary education per se in the distribution of art gallery attendance.

Chris and Lucas represent two very different poles of experiences that would be common enough in contemporary Western societies given the scale of the financial and cultural industries. They offer an insight into the formation of different taste cultures and how individuals can become 'placed' in art publics at an early age. It suggests perhaps, the value of art education and art museum going as well as the innovative approach that Mona has taken as an exhibitionary platform.

Mona succeeded by concentrating more on the political and moral subjects of contemporary art as a way of promoting its relevance and allure. Crucially perhaps, Mona gives children (and their parents), the opportunity to explore and consider socially contentious topics. The opportunity to discuss death, bodily functions, drug use and sex are thematically presented in the art. Mona ensures an equal footing for all visitors thus enabling intimate discussions that at times are thoughtful and potentially life altering. Mona is a positive yet underdetermined experience for children, reflected in their constant references to the art there as being 'cool' or 'weird'. It provides creative opportunity to connect with their parents and for them to explore, be fascinated by and entertained in an environment that recognizes and respects their individuality. Mona has an engaging grammar for children that oscillates between incitements to respond physically, joyfully - even outrageously - and incidents that pull them up suddenly, quietening them and provoking a more interior or conferred response. There is little that does not force a reaction from them, and hence few are ever emotionally neutral or bored. Children have a degree of agency in Mona that is denied them in many other exhibitionary platforms.

Children identified and recognized that Mona was not a 'proper museum'. To some extent Mona has come full circle in terms of the history of museums. There are elements of the fairground that embrace all and entertain; it is not concerned with the power and status - or even the cultural politics once associated with public art - but aims to provide a confronting, 
emotionally challenging experience more reminiscent of the wunderkammer and its connection to the excitements of contemporary questions of the day. And possibly, as demonstrated by our small sample of eight year olds, a new kind of disposition, not merely to know about, but to relate to and enjoy art.

Received: 2 August 2017

Finally Accepted: 27 March 2018

\section{Acknowledgement}

I would like to acknowledge that research for this article was made possible through funding from the Australian Research Council for the project 'Creating the Bilbao Effect: MONA and the Social and Cultural Coordinates of Urban Regeneration Through Arts Tourism'. LP120200302

\section{Note}

1 It should be noted that Mona does not run a schools programme and so its popularity is seemingly unprompted by adults. Mona welcomes anyone who wishes to visit, including school groups.

\section{References}

Anderson, D., Piscitelli, B., \& Everett, M. (2008) ‘Competing Agendas: Young Children's Museum Field trips' Curator , 51 (3), 253-273.

Bennett, T. (1995) The Birth of the Museum, London: Routledge.

Bourdieu, P. (1984) Distinction. A Social Critique of the Judgement of Taste, Oxon: Routledge.

Capon, E. (Director). (2013) The Art of Australia : A Three Part Documentary [Motion Picture]. Sydney.

Dockett, S., Main, S., \& Kelly, L. (2011) 'Consulting Young Children: Experiences from a Museum', Visitor Studies , 14 13-33

Examiner. (1921, January 18) 'Impossible to Struggle On. Same vote as in 1892. Childrens Room Wanted', Examiner (Launceston, Tas: 1900-1954), p. 7.

Foucalt, M. (1980) 'The Eye of Power', in Colin Gordon (ed) Power and Knowledge: Selected Interviews and Other Writings, 1972-1977, New York: Pantheon Books.

Franklin, A. (2014) The Making of Mona, Victoria: Penguin Publishing.

Franklin, A. and Papastergiadis, N. (2017) 'Engaging with the anti-museum? Visitors to the Museum of Old and New Art (Mona)', Journal of Sociology, 53 (3), 670-686.

Frow, J., Bennett, T. \& Emmison, M. (1999) Accounting for Tastes: Australian Everyday Culture, Cambridge: Cambridge University Press.

Griffin, J. (2011) 'The Museum education mix: student teachers and museum educators' in D. Griffin \& L. Paroissien (eds) Understanding Museums: Australian Museums and Museology, Canberra: National Museum of Australia.

Hackett, A. (2014) 'Zigging and zooming all over the place: Young children's meaning making and movement in the museum' Journal of Early Childhood Literacy, 14 (1) $5-27$. 
Hardman, C. (2001) 'Can there be an anthropology of Children?' Childhood, 8 (4) 501-517

Hicks, M. (2005) '“A whole new world": the young person's experience of visiting Sydney Technology Musuem', Musuem and Society, 3 (2) 66-80.

Hudson, K. (1975) A Social History of Museums, London: MacMillan Press.

James, A., \& Prout, A. (Eds.) (1997). Constructing and reconstructing childhood (2nd ed.), London: Falmer Press

Jeffers, C. (1999) 'When Children Take the Lead in Exploring Museums with their Adult Partners', Art Education, 52 (6) 45-51.

Larsen, J., \& Svabo, C. (2014) 'The Tourist gaze and "Family Treasure Trails" in museums' Tourist Studies, 14 (2) 105-125.

Lorenz, J.P. (2011) The Museums of Contemporaty Art, Farnham: Ashgate.

Mayfied, M. (2005) 'Mona Children's museums: purposes, practices and play?' Mona Early Child Development and Care, 175 (2) 179-192.

McManus, P. (1994) 'Families in Musuems', in R. Miles, \& L. Zavala (eds) Towards Musuems of the Future, London: Routledge.

O'Connor, J. (2013) 'David Walsh's MONA and the cultural regeneration of Hobart', The Conversation, July 8. https://theconversation.com/david-walshs-Mona-and-thecultural-regeneration-of-hobart-15718.

Piscitelli, B. (2011) 'What's driving children's cultural participation', in D. Griffin, \& L. Paroissien (eds) Understanding Museums: Australian Museums and Museology, National Museum of Australia, published online at nma.gov.au/research/ understandingmuseums.

Prout, A., \& James, A. (1997) 'A New Paradigm for the Sociology of Childhood? Provenance, Promise and Problems' in A. Prout, \& A. James (eds), Constructing and Reconstructing Childhood (2nd ed.), 7-33, London, England, United Kingdom: Falmer Press.

Roberts, (2006) 'Minor concerns: representations of children and childhood in British museums', Museums and Society, 4 (3) 152-165.

Smith, T. (2012) What is Contemporary Art? Chicago: Chicago University Press.

Weiner, K. (2004) 'Empowering Young Children In Art Museums: letting them take the lead', Contemporary Issues in Early Childhood, 5 (1) 106-116.

Wright, P. (1989) 'The Quality of Visitors' Experiences in Art Museums', in Peter Vergo (ed) The New Museology, 119-48, London: Reaktion Books.

*Adrian Franklin (School of Creative Industries, University of South Australia),

**Michelle Sansom (School of Social Sciences, University of Tasmania)

Professor Adrian Franklin (corresponding author) Adrian.Franklin@unisa.edu.au

Creative Industries \& Cultural Policy

School of Creative Industries

University of South Australia 